\title{
Concise Commentary: Breathing New Life into Antisecretory Medications
}

\author{
Robert T. Kavitt ${ }^{1} \cdot$ Michael F. Vaezi $^{2}$
}

Published online: 27 December 2017

(c) Springer Science+Business Media, LLC, part of Springer Nature 2017

\section{Background}

Lung transplantation is a high-risk procedure with a 53\% survival at 5 years and median survival of 5.7 years [1]. Gastroesophageal reflux disease (GERD) and aspiration of gastric contents injure the allograft, leading to the bronchiolitis obliterans syndrome. Although studies have assessed the benefits of antireflux surgery in lung transplant recipients, there is a paucity of literature assessing the therapeutic utility of acid suppression in this patient population.

\section{Summary of Findings}

In this issue of Digestive Diseases and Sciences, Lo et al. [2] performed a retrospective cohort study assessing 188 adult lung transplant recipients from 2007 to 2014 . They retrospectively reviewed medical records in order to determine the timing and duration of exposure to proton pump inhibitors (PPIs) and histamine-2 receptor antagonists (H2RAs) after transplantation. A total of 115 patients developed acute or chronic rejection. The use of any medical acid suppression was associated with significant reduction in rejection with a hazard ratio of $0.37(p=0.03)$. Persistent use of PPI was associated with greater protection against rejection compared with no acid suppression (HR 0.32, $p=0.02$ ). The protection against rejection was independent of body mass index and was most robust with persistent use of PPI. Persistent use of PPI provided increased protection over persistent therapy with H2RA.

Michael F. Vaezi

Michael.Vaezi@Vanderbilt.edu

1 Section of Gastroenterology, Hepatology, and Nutrition, University of Chicago, Chicago, IL, USA

2 Division of Gastroenterology, Hepatology and Nutrition, Vanderbilt University Medical Center, 1660 TVC, 1301 22nd Ave. South, Nashville, TN 37232-5280, USA

\section{Discussion}

These intriguing findings should serve as the basis for future prospective trials to confirm these important retrospective findings and to further elucidate the mechanism by which acid suppression with PPIs may favorably impact outcomes for lung transplant recipients. PPIs may have anti-inflammatory properties beyond acid-suppressive mechanisms [3], which may be of added benefit in patients with pulmonary disease and in those who have undergone lung transplantation.

As the authors note, given the retrospective study design, assessment of GERD symptoms was not standardized at the time of the outpatient follow-up visits, diminishing the quality of data with regard to symptom assessment that may have prompted the prescription of acid-suppressive medications. Furthermore, objective reflux data such as pH-metry and endoscopic mucosal assessment were not included.

These findings represent an important contribution to an area where evidence-based guidance is sorely needed. As the authors suggest, studies with additional endpoints including mortality, as well as comparison to antireflux surgery outcomes, should be important goals of future prospective research.

\section{References}

1. Yusen RD, Edwards LB, Kucheryavaya AY, et al. The registry of the International Society for Heart and Lung Transplantation: thirty-first adult lung and heart-lung transplant report-2014; focus theme: retransplantation. J Heart Lung Transplant. 2014;33:1009-1024.

2. Lo WK, Goldberg HJ, Boukedes S, Burakoff R, Chan WW. Proton Pump Inhibitors Independently Protect Against Early Allograft Injury or Chronic Rejection After Lung Transplantation. Dig Dis Sci. (Epub ahead of print). https://doi.org/10.1007/ s10620-017-4827-0.

3. Kedika RR, Souza RF, Spechler SJ. Potential anti-inflammatory effects of proton pump inhibitors: a review and discussion of the clinical implications. Dig Dis Sci.. 2009;54:2312-2317. 